\title{
Fatigue, alcohol, and serious road crashes in France: factorial study of national data
}

\author{
P Philip, F Vervialle, P Le Breton, J Taillard, J A Horne
}

France has a high rate of road traffic crashes. ${ }^{1}$ Although driver fatigue may be an important factor, ${ }^{2-4}$ it has not been investigated in France, and no comparisons have been made with alcohol related crashes. ${ }^{5}$ We investigated the role of fatigue in serious road crashes using the French national database. ${ }^{1}$

\section{Methods and results}

We obtained data from the French Ministry of Transport on all road crashes during 1994-8 (640 670) in which at least one person was severely injured (confirmed by paramedics) or died. Crashes were attended by police officers, who completed a standard ministry questionnaire that covered time of incident, location, road and weather conditions, vehicles involved, mechanical defects, health of driver, and alcohol consumption as well as giving summaries of interviews and probable causes.

As crashes related to fatigue can be difficult to identify, we applied the strict criteria of Horne and Reyner to eliminate many of the confounding factors. ${ }^{2}$ We assessed only single vehicle crashes that occurred during good weather and road conditions on roads unrestricted by junctions. This excluded most urban road crashes (comprising most crashes), crashes involving pedestrians, and those in which the driver reported taking medication or was suspected to have used illicit drugs. This left 67671 crashes for analysis.

We identified four categories of crash:

Alcohol related-Blood alcohol concentration $>100$ mg ethanol/1 1 blood (breathalyser or blood analysis).

Fatigue related-Driver could have avoided crash but no avoidance taken (no braking or swerving), with blood alcohol concentration $<100 \mathrm{mg} / \mathrm{l}$.

Alcohol and fatigue related-Fatigue related crash with driver's blood alcohol concentration $>100 \mathrm{mg} / \mathrm{l}$.

No alcohol or fatigue - No fatigue; blood alcohol concentration $<100 \mathrm{mg} / \mathrm{l}$.

About 10\% (6770) of the crashes were related to fatigue and 23\% (15 670) to alcohol (table 1). These were subdivided into three periods: day (0700-1959), evening (2000-2359), and early morning (0000-0659). Alcohol related crashes were more likely to be fatal during the evening and early morning compared with the daytime (Wald's $\chi^{2}=4.88, \mathrm{P}=0.02$ for evening, $\chi^{2}=18.04, \mathrm{P}<0.01$ for early morning), whereas fatigue related crashes were more likely to be fatal during the day than the early morning $\left(\chi^{2}=5.37, \mathrm{P}=0.02\right)$.

For the whole 24 hours, and compared with all other non-alcohol related crashes, the relative risk of death in crashes related to fatigue was 1.65 (95\% confidence interval 1.49 to $\left.1.82, \chi^{2}=97.09, \mathrm{P}=0.001\right)$. The risk of severe injuries was 1.5 (1.4 to $1.6, \chi^{2}=226.15$, $\mathrm{P}=0.001)$.

For alcohol related crashes, the relative risk was 4.2 (3.9 to $\left.4.4, \chi^{2}=2517, \mathrm{P}=0.001\right)$ for death and 1.9 (1.8 to 2.0, $\chi^{2}=1057, \mathrm{P}=0.001$ ) for severe injuries. For

\begin{tabular}{|c|c|c|c|}
\hline Time & $\begin{array}{l}\text { No of } \\
\text { crashes }\end{array}$ & $\begin{array}{c}\text { No (\%) with } \\
\text { deaths* }\end{array}$ & $\begin{array}{l}\text { No (\%) with severely } \\
\text { injured victims* }\end{array}$ \\
\hline \multicolumn{4}{|c|}{ No fatigue, no alcohol: } \\
\hline $0000-0659$ & 8829 & $532(23)$ & $3031(21)$ \\
\hline $0700-1959$ & 27711 & $1304(57)$ & $8780(60)$ \\
\hline $2000-2359$ & 7909 & $459(20)$ & 2790 (19) \\
\hline \multicolumn{4}{|c|}{ Fatigue, no alcohol: } \\
\hline $0000-0659$ & 2419 & $180(32)$ & $1112(38)$ \\
\hline $0700-1959$ & 3833 & $349(62)$ & $1617(56)$ \\
\hline $2000-2359$ & 518 & $35(6)$ & $183(6)$ \\
\hline \multicolumn{4}{|c|}{ Alcohol, no fatigue: } \\
\hline $0000-0659$ & 7423 & $1549(51)$ & $3735(51)$ \\
\hline $0700-1959$ & 4088 & $733(24)$ & $1714(23)$ \\
\hline $2000-2359$ & 4159 & $785(26)$ & $1937(26)$ \\
\hline \multicolumn{4}{|c|}{ Alcohol and fatigue: } \\
\hline $0000-0659$ & 464 & $123(56)$ & $263(66)$ \\
\hline 0700-1959 & 228 & $77(35)$ & $104(26)$ \\
\hline $2000-2359$ & 90 & $18(8)$ & $33(8)$ \\
\hline
\end{tabular}

${ }^{*}$ Percentages are given for sum of each category.

alcohol and fatigue combined, the risk of death was 6.8 (5.7 to $\left.8.0, \chi^{2}=678, \mathrm{P}=0.001\right)$ and risk of severe injuries $2.6\left(2.2\right.$ to $\left.3.0, \chi^{2}=141, \mathrm{P}=0.001\right)$.

We then ran a multivariate analysis on daytime crashes with death as the dependent variable and fatigue, physical handicap, distraction (driver alert but attending elsewhere), and weekend (versus weekday) as independent variables. For non-alcohol related crashes resulting in death, the significant factors were fatigue (odds ratio $=1.57,95 \%$ confidence interval 1.42 to $1.74, \mathrm{P}<0.001)$, distraction $(0.70,0.61$ to 0.82 , $\mathrm{P}<0.001)$, and weekends $(1.14,1.05$ to $1.23, \mathrm{P}<0.001)$. For alcohol related crashes resulting in death, only fatigue was significant $(1.41,1.15$ to $1.73, \mathrm{P}<0.001)$.

\section{Comment}

We found that fatigue, especially when combined with alcohol, presents a particularly high risk of road crashes resulting in death or serious injury. This has been largely unrecognised in France and elsewhere. There was also a strong relation between time of day and cause of crash, with many alcohol related crashes occurring at night. However, it is likely that police officers will attribute such crashes only to alcohol, even when fatigue is present.

We thank Annie Canel and Michel Labrousse, Service d'Études Techniques des Routes et Autoroutes, for help in organising and Bernard Bioulac, department of neurophysiology, Bordeaux University Hospital, for his support.

Contributors: PP participated in the design and analysis of the study. PLB and FV participated in the statistical analysis. JT and JAH helped with the methodology.

The paper was written jointly by PP, FV, JT, and JAH. PLB is the guarantor.

Funding: This study was sponsored by the Service d'Études Techniques des Routes et Autoroutes.

Competing interests: None declared.
Editorial by Feyer

Clinique du

Sommeil, Centre

Hospitalier

Universitaire,

Bordeaux 33076 ,

France

P Philip

consultant

J Taillard

research assistant

Service d'Études

Techniques des

Routes et

Autoroutes,

Bagneux, France

F Vervialle

statistician

P Le Breton

statistician

Sleep Research

Laboratory,

Loughborough

University,

Loughborough

LE11 3TU

$\mathrm{J}$ A Horne

professor

Correspondence to:

P Philip

pierrephilip@

compuserve.com

BMJ 2001;322:829-30 
1 Observatoire National Interministériel de la Sécurité Routière. Bilan annuel statistiques et commentaires. Paris: Ministère des Transports, 1999. Horne JA, Reyner LA. Sleep related vehicle accidents. BMJ 1995;310:565-7.

3 Philip P, Ghorayeb I, Stoohs R, Menny JC, Dabadie P, Bioulac B, et al. Determinants of sleepiness in automobile drivers. $J$ Psychosomatic Res 1996; $41: 279-88$
4 Philip P, Taillard J, Guilleminault C, Quera Salva MA, Bioulac B, Ohayon $\mathrm{M}$. Long distance driving and self induced sleep deprivation among automobile drivers. Sleep 1999;22:475-80.

5 Biecheler MB, Filou C, Fontaine H. Conduite automobile et accidents liés à l'alcool. Références et résultats 1985 et 1995. Arceuil: INRETS Publishers, 1995.

(Accepted 21 December 2000)

\title{
Relation between socioeconomic status and tumour stage in patients with breast, colorectal, ovarian, and lung cancer: results from four national, population based studies
}

\author{
David H Brewster, Catherine S Thomson, David J Hole, Roger J Black, Paul L Stroner, \\ Charles R Gillis on behalf of the Scottish Cancer Therapy Network
}

Scottish Cancer Intelligence Unit, Information and Statistics Division, Trinity Park House, Edinburgh EH5 3SQ David H Brewster director of cancer registration in Scotland

Catherine S

Thomson

senior statistician

Roger J Black

head

Paul L Stroner

coordinator of the

Scottish Cancer

Therapy Network

West of Scotland

Cancer Surveillance

Unit, Department of

Public Health,

University of

Glasgow, Glasgow

G12 8RZ

David J Hole

deputy director

Charles R Gillis

director

Correspondence to: D H Brewster

David.Brewster@

isd.csa.scot.nhs.uk

BMJ 2001;322:830-1

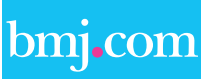

A table showing the availability of medical records by socioeconomic status appears on the BMJ's website
Although there is evidence that patients with cancer from deprived communities in Scotland might present with more advanced disease, ${ }^{1-3}$ this finding has not been replicated in every study. ${ }^{4}$ Using data from four population based audits, we investigated whether there is any relation between socioeconomic status and tumour stage at presentation in patients with breast, colorectal, ovarian, and lung cancer.

\section{Participants, methods, and results}

For each audit potential study populations were identified from the Scottish Cancer Registry, and data were abstracted from medical records. The years of diagnosis for patients with breast, colorectal, ovarian, and lung cancer were 1993, 1993, 1992-4, and 1995, respectively.

The staging details examined were: pathological size, pathological nodal status, and metastatic status for breast cancers; Dukes' stage for colorectal cancers; Fédération Internationale de Gynécologie et d'Obstétrique stage for ovarian cancers; and a simple extent of disease classification based on clinical findings or investigations for lung cancers (as only $11 \%$ of cases had surgical resection), or both.

Medical records were available for 2518 patients with breast cancer, 2778 with colorectal cancer, 1387 with ovarian cancer, and 3855 with lung cancer, representing more than $90 \%$ of potentially eligible cases for each of the four cancer sites. A higher proportion of records was unobtainable for deprived than for affluent patients with lung cancer $(11.7 \%$ v $7.0 \%, \mathrm{P}<0.001)$ (see table on website). No significant differences were found in availability of medical records by deprivation grouping for the other cancers.

The table shows the distributions of variables for tumour staging by cancer site and deprivation grouping. P values for associations between the staging variables and deprivation were similar when unknown stages were excluded. We found no evidence that patients from deprived communities were likely to present with more advanced disease for breast or colorectal cancer. For ovarian cancer there was a possibility that deprived patients may have more advanced disease (see table); however, deprived patients with lung cancer were more likely to present with localised disease (see table). Multivariate analyses, performed using log linear modelling, showed no evidence of age dependent relations between stage of disease and deprivation. The four age groups used for these analyses differed by cancer site because they were predefined by different specialist groups-for example, the breast cancer specialists included a category for screening age group (50-64 years).

\section{Comment}

We found no consistent evidence that patients from deprived communities present with more advanced disease for breast, colorectal, ovarian, or lung cancer. Despite the introduction of breast screening and differential uptake by socioeconomic status, ${ }^{5}$ our results for breast cancer remain similar to those of Carnon et al. $^{4}$ However, another recent but smaller study from the west of Scotland found that women from deprived areas were more likely to present with locally advanced or metastatic disease. ${ }^{3}$ Our result for colorectal cancer conflicts with those of a study from Tayside, although the latter was based on cases for which there was a record of disease, and so not population based, and excluded patients with distant metastases. ${ }^{2}$ The result for ovarian cancer was of borderline significance, although patients with stage unknown had a generally worse prognosis than those with stage IV disease, presumably reflecting inoperability. The greater likelihood of deprived patients with lung cancer presenting with localised disease could be an artefact resulting from differential availability of medical records across the socioeconomic groupings or, owing to comorbidity, less intensive investigation of these patients leading to less accurate data for staging. Alternatively, it might reflect a lower threshold for investigation and referral in patients from deprived communities presenting with suspicious symptoms, because they are more likely to be current smokers. Further research is needed to investigate the contribution of tumour, host, and treatment related factors to outcome. 